\title{
Can Airway Abnormalities be the Elephant in the Room in Children with Congenital Heart Disease?
}

\author{
Narayanan Parameswaran
}

\author{
Indian Journal of Critical Care Medicine (2020): 10.5005/jp-journals-10071-23424
}

Pediatric flexible bronchoscopy (FB) has evolved from being a curiosity in the 1970s to an essential tool in the pediatric ICU by the millennium. ${ }^{1-3}$ From the time the first American Thoracic Society (ATS) guidelines were published in 1992, the indications and adoption of FB, both in general pediatrics and in intensive care, have been expanding rapidly. In the general pediatric population, FB was mainly used to help in the diagnosis of suspected airway anomalies and in the evaluation of recurrent/persistent pneumonia. ${ }^{3}$ The benefit of the procedure in terms of diagnostic yield and clinically meaningful change in management has been well documented. In most pediatric literature on $\mathrm{FB}$, the additional information obtained from $F B$ resulted in clinically meaningful change in management to the extent of $67-90 \%{ }^{5,6}$ Since most FB happens in the PICU, pediatric intensive care physicians are being routinely trained in $\mathrm{FB}$. There is increasing recognition of its contribution to patient care in the PICU. In one of the earliest published series involving children admitted exclusively in the PICU, evaluation of extubation failure was the most common indication for FB. ${ }^{7}$ Even though the rate of positive findings was comparatively lower (69\%) in this series, the management changed from conservative to surgical in $39 \%$ of children after FB. ${ }^{7}$ With widespread use of FB in the PICU, its benefits have been employed in an expanding array of management conundrums including difficult endotracheal intubation, guide to surgical interventions, decannulation or change of tracheostomy tube, etc. ${ }^{3}$

With the decline in the burden of childhood infections, children with cardiac anomalies constitute a significant proportion of admission to the PICU. Many hospitals in the developed world, and increasingly in our country too, have a separate division of PICU catering to these children. Children with cardiac anomalies tend to have higher incidence of airway anomalies. ${ }^{8}$ Few authors from the developed world have looked specifically at this population of children and found that FB requirement may be higher in this population. ${ }^{9-11}$ This month, in our journal, we have Sachdev et al. reporting their experience of FB in this patient population. ${ }^{12}$ They have retrospectively analyzed the case records of children with congenital heart disease (CHD) who underwent FB in their PICU over a period of 6 years. The data are valuable as there is little information on this area from the developing world. Among the $78 \mathrm{FB}$ procedures carried out in 58 patients, more than half (53.5\%) were done preoperatively, persistent atelectasis and prolonged ventilation accounting for $74 \%$ of the indications. Among the children who underwent FB postoperatively, persistent atelectasis and persistent oxygen requirement accounted for $87 \%$ of the procedures. Thus, the indications for FB in both preand postoperative children were similar. Interestingly, the major findings (tracheomalacia and tracheobronchitis) were also similar in both the preoperative and postoperative children, the only major
Department of Pediatrics, Jawaharlal Institute of Postgraduate Medical Education and Research, Puducherry, India

Corresponding Author: Narayanan Parameswaran, Department of Pediatrics, Jawaharlal Institute of Postgraduate Medical Education and Research, Puducherry, India, Phone: +91 9443458850, e-mail: narayanan.p@jipmer.edu.in

How to cite this article: Parameswaran N. Can Airway Abnormalities be the Elephant in the Room in Children with Congenital Heart Disease? Indian J Crit Care Med 2020;24(5):289-290.

Source of support: Nil

Conflict of interest: None

difference being the diagnosis of extrinsic compression of airways being more common in preoperative patients (32\%). The authors have reported that more than half $(53.5 \%)$ of the FB procedures resulted in further therapeutic interventions. Among these $(n=38)$, $29 \%$ resulted in change in antibiotics, $26 \%$ led to further diagnostic imaging (CT angiography), and 26\% were followed by surgical interventions for airway. It is also pertinent to note that a significant number of airway anomalies were detected in the postoperative period. This includes the findings of tracheobronchomalacia (37\%) and abnormal branching of airways (10\%) among children who underwent FB in the postoperative period. It can be safely assumed that these anomalies were asymptomatic and were diagnosed in the postoperative period while evaluating for persistent atelectasis, oxygen dependency, etc. There could be many reasons for preexisting clinically nonevident airway obstruction to manifest in the postoperative period. The distortion of the anatomic relationship between the tracheobronchial tree and the vascular structures caused by the surgery, airway damage sustained during intubation, and postoperative mechanical ventilation and infections being the major contributors. ${ }^{13}$

Though others have reported that FB contributed to patient management in a clinically meaningful manner in $91 \%$ of the time, comparison across studies is challenging, given what constitutes the definition of "clinically meaningful" contribution. ${ }^{5} \mathrm{~A}$ normal FB finding may be considered reassuring and hence can also be counted as "clinically meaningful" by some. ${ }^{3}$ Though the real burden of airway issues in children with CHD can be brought out only by a prospective study evaluating all children with CHD, such a study may never be done due to obvious logistical and ethical issues. An indirect albeit imprecise way of assessing that burden may be to estimate the proportion of children admitted with CHD who required FB during their hospital stay. The authors of the present study have not reported that.

(c) The Author(s). 2020 Open Access This article is distributed under the terms of the Creative Commons Attribution 4.0 International License (https://creativecommons. org/licenses/by-nc/4.0/), which permits unrestricted use, distribution, and non-commercial reproduction in any medium, provided you give appropriate credit to the original author(s) and the source, provide a link to the Creative Commons license, and indicate if changes were made. The Creative Commons Public Domain Dedication waiver (http://creativecommons.org/publicdomain/zero/1.0/) applies to the data made available in this article, unless otherwise stated. 
Airway obstruction by extrinsic compression requires a special mention as the occurrence of the same could be higher in children with CHD, due to the presence of abnormally dilated chambers and great vessels in many of them. ${ }^{9,10}$ In the present study by Sachdev et al., $18 \%$ of children among those who underwent FB in the PICU (both preoperative and postoperative combined) had external airway compression. Dilated pulmonary arteries (either left or right) and dilated left atrium accounted for $90 \%$ of extrinsic airway compressions in the present study. Yamaguchi et al. had published their experience over 15 years on the occurrence of airway obstruction in children due to CHD. ${ }^{10}$ Among their study population of 98 children, $87 \%$ had airway obstruction due to external compression, $9 \%$ of which disappeared after heart surgery. They concluded that external compression of airways should always be ruled out in children having difficulty in coming off a ventilator after successful cardiac surgery. ${ }^{10}$

It is reassuring that the authors of the present study did not encounter any major complications during FB in their children. The low rate of major complications reported by most investigators is encouraging considering the high-risk population in whom most of these FB procedures are performed.

It is a common observation among pediatric intensivists that infants with CHD have a tendency to require prolonged mechanical ventilation. These children have frequent admissions due to cardiac decompensation and recurrent respiratory infections and any prolonged ventilator requirement is usually attributed to the underlying cardiac condition and poor cardiac reserve. The study by Sachdev et al. is a reminder that airway abnormalities should be actively looked for in these children, which when present may alter the management with potential for improving their clinical course and final outcome.

\section{References}

1. Wood RE, Fink RJ. Applications of flexible fiberoptic bronchoscopes in infants and children. Chest 1978;73(5 Suppl):737-740. DOI: 10.1378/ chest.73.5_Supplement.737.
2. Wood RE, Sherman JM. Pediatric flexible bronchoscopy. Ann Otol Rhino Laryngol 1980;89(5 Pt 1):414-416. DOI: 10.1177/000348948008900506.

3. Nussbaum E. Pediatric fiberoptic bronchoscopy: clinical experience with 2,836 bronchoscopies. Pediatr Crit Care Med 2002;3(2):171-176. DOI: 10.1097/00130478-200204000-00015.

4. Green CG, Eisenberg J, Leong A, Nathanson I, Schnapf BM, Wood RE. Flexible endoscopy of the pediatric airway. Am Rev Respir Dis 1992;145(1):233-235. DOI: 10.1164/ajrccm/145.1.233.

5. Godfrey S, Avital A, Maayan C, Rotschild M, Springer C. Yield from flexible bronchoscopy in children. Pediatr Pulmonol 1997;23(4): 261-269. DOI: 10.1002/(SICI)1099-0496(199704)23:4<261::AIDPPUL3>3.0.CO;2-P.

6. Costa AdS, Scordamaglio PR, Suzuki I, Palomino ALM, Jacomelli M. Indications, clinical outcomes and complications of 1,949 flexible bronchoscopies. Einstein Sao Paulo Braz 2018;16(4):eAO4380. DOI: 10.31744/einstein_journal/2018AO4380.

7. Bar-Zohar D, Sivan Y. The yield of flexible fiberoptic bronchoscopy in pediatric intensive care patients. Chest 2004;126(4):1353-1359. DOI: 10.1378/chest.126.4.1353.

8. Kockar T, Gunduz M, Oktem S, et al. Bronchoscopic findings in children with congenital heart disease. Eur Respir J 2015;46(suppl 59):PA1355. DOI: 10.1183/13993003.congress-2015.PA1355.

9. Chapotte C, Monrigal JP, Pezard P, Jeudy C, Subayi JB, De Brux JL, et al. Airway compression in children due to congenital heart disease: value of flexible fiberoptic bronchoscopic assessment. J Cardiothorac Vasc Anesth 1998;12(2):145-152. DOI: 10.1016/S1053-0770(98) 90321-4.

10. Yamaguchi D, Tanigami H, Suematsu Y, Murakami A, Kitsuta Y, Ishii T, et al. Airway obstruction in children due to congenital heart disease (our 15 years experience). Jpn J Trauma Emerg Med 2012;3(1):17-24. DOI: $10.11176 /$ jjtem.3.17.

11. Lee SL, Cheung YF, Leung MP, Ng YK, Tsoi NS. Airway obstruction in children with congenital heart disease: assessment by flexible bronchoscopy. Pediatr Pulmonol 2002;34(4):304-311. DOI: 10.1002/ ppul.10164.

12. Sachdev A, Chhawchharia R, Gupta D, Gupta N, Joshi R, Agarwal N. Flexible fiberoptic bronchoscopy-directed interventions in children with congenital heart diseases. Indian J Crit Care Med 2020;24(5): 340-343.

13. Corno A, Giamberti A, Giannico S, Marino B, Rossi E, Marcelletti C, et al. Airway obstructions associated with congenital heart disease in infancy. J Thorac Cardiovasc Surg 1990;99(6):1091-1098. 